Running Head: ATHLETE BRAND DEVELOPMENT VIA PHILANTHROPY

\title{
Becoming more than an athlete: Developing an athlete's personal brand using strategic philanthropy
}

\author{
Thilo Kunkel, Temple University \\ Jason Doyle, Griffith University \\ Sangwon Na, Temple University
}

European Sport Management Quarterly, DOI: 10.1080/16184742.2020.1791208

\section{Thilo Kunkel}

Temple University, Sport and Recreation Management

Speakman Hall 315, 1810 N 13th St

Philadelphia, PA, 19122, USA

Email: thilo.kunkel@temple.edu

Phone: +1 2152040307

\section{Jason Doyle}

Griffith University, Griffith Business School - Department of Tourism, Sport and Hotel Management

Glyn Davis Building N72 0.40, Nathan Campus

Nathan, QLD, 4111, Australia

Email: Jason.doyle@griffith.edu.au

Phone: +61 737356742

\section{Sangwon Na}

Temple University, Sport and Recreation Management

Speakman Hall 111, 1810 N 13th St

Philadelphia, PA, 19122, USA

Email: sangwon.na@temple.edu

Phone: + 1850 688-3342

Acknowledgement: The authors are grateful for the support from the Sport Industry Research Center at Temple University. 


\section{Becoming more than an athlete: Developing an athlete's personal brand using strategic philanthropy}

Research Question: The current research examined the effect of an athlete promoting his philanthropic efforts to his Instagram followers. Specifically, we assessed how adopting this strategy impacted his followers' perceptions of, and level of fandom towards, his personal brand.

Research Methods: We used a longitudinal research design including a pre-intervention survey, an intervention, and a post-intervention survey separated by a six-month interval. We analysed free-thought brand associations, perceptions of athlete philanthropy, and levels of fandom reported by an athlete's Instagram followers from two independent samples $\left(N_{\mathrm{T} 1}=\right.$ $\left.165 ; N_{\mathrm{T} 2}=172\right)$ and a longitudinal sample $(N=32)$.

Results and Findings: Results indicated that the athlete's promotion of his philanthropic activities positively impacted his brand image. This change was characterised by a shift from the prominence of sport-specific brand attributes to perceptions of overall character. In addition, followers reported increased perceptions of the athlete's engagement in philanthropy, and stronger levels of overall fandom towards the athlete.

Research Implications: Findings demonstrated the promotion of philanthropic activities impacted the brand associations consumers linked to the athlete's personal brand, and strengthened the overall connection between the athlete and his followers. Findings extend athlete branding knowledge and provide practical implications to inform how athletes and agents may implement social media brand management.

Keywords: Athlete brands, athlete philanthropy, brand image, sport consumers, social media 
Athletes are increasingly leveraging their social media following to promote their philanthropic efforts. For example, FC Bayern Munich players Joshua Kimmich and Leon Goretzka raised over $€ 3.5$ million for charitable projects through their "We Kick Corona" campaign, which was largely driven via their social media accounts. Another example is Houston Texans superstar J.J. Watt who launched a campaign to raise $\$ 200,000$ in support for the victims of Hurricane Harvey, which devastated the city of Houston. Watt promoted this target to his social media followers and the campaign raised over US\$37 million. In addition to this fundraising, Watt increased his Twitter following by over 300,000 during the first month of the fundraiser alone (Trackalytics, 2017) and was endorsed to receive the NFL's Man of the Year award (Rapaport, 2017). Similarly, Major League Soccer (MLS) awards the Humanitarian of the Year Award to players who support charitable efforts and serve their communities through their MLS WORKS community outreach program (MLS WORKS, 2019). Overall, the above examples demonstrate how athlete philanthropy can result in significant fundraising and awareness for important causes, and show increased emphasis on recognising athlete philanthropy. However, little is known about how consumers perceive athlete philanthropy from a brand management perspective.

Athletes are popular and highly recognised individuals who consumers evaluate as brands (Carlson \& Donavan, 2008, 2013). As such, scholars have begun to examine athlete brands, paying particular concern to understanding the dimensions which contribute to consumers' overall perceptions of them (Arai, Ko, \& Kaplanidou, 2013; Arai, Ko, \& Ross, 2014; Kunkel, Biscaia, Arai, \& Agyemang, 2020). Although the altruistic outcomes generated by philanthropy are well understood, less is known about how engaging in and promoting these activities may impact consumer perceptions of athlete brands (e.g., Babiak, Mills, Tainsky, \& Juravich, 2012). Existing athlete branding frameworks, such as the Model of Athlete Brand Image (MABI) (Arai et al., 2013; Arai et al., 2014), provide a theoretical 
basis to consider how athletes may leverage various types of content to influence consumers' perceptions of, and overall level of connection to, their personal brands. Within this research, we focus specifically on how the promotion of athletes' philanthropic activities impact consumer perceptions of their personal brands.

Philanthropy is defined as "the synergistic use of organizational core competencies and resources to address key stakeholders' interests and to achieve both organizational and social benefits" (McAlister \& Ferrell, 2002, p. 690). Research on consumer perceptions of organizational brands has shown that a company's strategic involvement with socially responsible initiatives (e.g., philanthropy), can positively shape consumer attitudes towards their brands (Baalbaki \& Guzman, 2016; Guzman \& Davis, 2017; Husted \& Allen, 2007). Scholars have similarly theorized that athletes involved with philanthropic initiatives may generate positive outcomes (e.g., Babiak et al., 2012; Choi \& Berger, 2010; Hasaan, Kerem, Biscaia, \& Agyemang, 2018). Building on these theoretical propositions, the present research addresses calls from the literature to further examine how athletes can strategically develop their brands to better connect with consumers (e.g., Carlson \& Donavan, 2008, 2013; Geurin, 2017; Kunkel et al., 2020) via the promotion of their philanthropy.

We specifically focus on exploring how social media platforms can be used for branding purposes, as the reach, accessibility, and highly personal nature of social media platforms provide opportunities for individuals to develop their personal brand ( $\mathrm{Su}, \mathrm{Baker}$, Doyle, \& Kunkel, 2020) for the purposes of gaining political, social, or financial benefits (Choi \& Berger, 2010). Sport management researchers contend the creation of social media has enabled athletes to take control of their branding message (Abeza, O’Reilly, Séguin, \& Nzindukiyimana, 2015; Filo, Lock \& Karg, 2015; Geurin, 2017) and promote their pursuits (including philanthropic endeavours) to others on a global scale (Babiak et al., 2012; Hayes, Filo, Geurin, \& Riot, 2020). Extant research has demonstrated that social media can be used 
as an effective means to augment a sport team's brand image to better build relationships with fans (Abeza et al., 2013; Anagnostopoulos, Parganas, Chadwick, \& Fenton, 2018). Similarly, research focused at the team level indicates marketing messaging can influence the brand associations sport consumers link with teams, and their overall connection towards the team over time (e.g., Kunkel, Doyle, Funk, Du, \& McDonald, 2016), providing an opportunity to examine how this relates to efforts at the individual athlete level. To do so, the current research explores how athletes can leverage the promotion of their philanthropic activities via social media to impact the perceptions, and overall sense of connection, consumers attach to their brands.

\section{Literature Review}

\section{Brand Image and Brand Associations}

An entity's brand image reflects the overall "perceptions about a brand as reflected by the brand associations held in consumer memory" (Keller, 1993, p.3). Sport leagues, teams, and individual athletes regard their brand images as important and seek to develop positive brand associations. Brand associations represent any benefit or attribute that an individual may link to a brand (Keller, 1993). Consumer networks of associations represent the product of an individual's pre-existing knowledge interacting with incoming information surrounding a brand (Till, 1998). Each association an individual links with an athlete, may be perceived positively or negatively and therefore influences their overall feelings towards the athlete's brand (e.g., Arai et al., 2013; Carlson \& Donavan, 2008, 2013). Changes in these association sets may also influence the athlete's overall brand image perceptions positively or negatively. Thus, brand associations are structured as an associative network (Keller, 1993) that help individuals form attitudes towards athletes by drawing upon the specific attributes and benefits they link to the athletes. 
Researchers have identified a series of attributes and benefits linked with sport leagues (Kunkel, Doyle, \& Funk, 2014) and teams (Gladden \& Funk, 2001; Ross, James, \& Vargas, 2006) which influence consumers' overall attitudes towards these organizations. For example, Doyle, Filo, McDonald, and Funk (2013) demonstrated that brand associations influence attitudinal loyalty of Australian sport consumers. More recent research has used a longitudinal approach to demonstrate how brand association perceptions change over time (Daniels, Kunkel, \& Karg, 2019) and can be influenced by using marketing communications (Kunkel, Doyle, et al., 2016). Collectively, this body of research demonstrates that consumers evaluate sport objects based on the various association sets that surround them, that associations are predictive of the overall connection between a consumer and a sport object, and that these associations can be augmented over time. Kunkel, Scott and Beaton (2016) highlighted the need for longitudinal research examining the impact of specific and targeted marketing strategies (e.g., promoting philanthropic activities) on consumer perceptions of athlete brands, yet empirical research addressing this call remains scant.

\section{Athlete Brands}

Whilst athletes have been long established as human brands (Carlson \& Donavan, 2008,2013 ) academic attention has thus far focused on the challenges that athletes face in developing their brands (e.g., Lobpries, Bennett, \& Brison, 2018), alongside the negative implications for athlete brands linked with transgressions (Lee \& Kwak, 2016; Sassenberg, 2015). Scholars argue that athletes are motivated to use their social media accounts for brand building purposes (Parganas, Anagnostopoulos, \& Chadwick, 2015), yet tend to lack a guiding strategy in their use of these platforms (Geurin, 2017). Therefore, opportunities exist to answer calls from the literature to examine the impact of positive social media messaging on athlete brands (Kunkel, Scott, et al., 2016). Consequently, we focused on examining how 
athletes can use social media to build their brands and draw upon the MABI (Arai et al., 2013; Arai et al., 2014) as the conceptual basis to guide our investigation.

The MABI posits that athlete brand image perceptions are a cumulative product of both the on-field and off-field associations (Hasaan et al., 2018) consumers link with athletes across three categories - Athletic Performance, Attractive Appearance, and Marketable Lifestyle (Arai et al., 2013; 2014). The first category, Athletic Performance, relates to an athlete's on-the-field performance characteristics. Four sub-categories contribute towards Athletic Performance perceptions: athletic expertise (e.g., the skills and proficiency of the athlete), competition style (e.g., how well the athlete performs or contributes towards the goals of the team), sportsmanship (e.g., the degree that the athlete performs with integrity and practices fair play; we renamed the dimension to sportspersonship to include all genders), and rivalry (e.g., the extent that the athlete possesses competitive rivalries with others). Given athletes are predominantly employed based on their athletic ability, athletic performance is key to establishing an athlete's brand image, and showcasing their best performance is the most effective way for an athlete to stand out from competitors (Braunstein \& Zhang, 2005).

The second category, Attractive Appearance, refers to the physical characteristics of an athlete (Arai et al., 2013). This category has three sub-categories: physical attractiveness (e.g., perceptions that the athlete is aesthetically appealing), symbol (e.g., perceptions that the athlete is unique, fashionable, or stylish) and body fitness (e.g., perceptions that the athlete possesses a healthy body image). Traditionally, sport teams have expressed their team logo, colours, and name to positively differentiate and brand themselves (Kunkel, Doyle, et al., 2016). Likewise, individual athletes can also express their attractive appearance or personal symbols to stand out from other athletes (Hodge \& Walker, 2015). For example, certain athletes are known for possessing unique body characteristics (e.g., Cristiano Ronaldo), 
fashion styles (e.g., David Beckham), or distinguishing hairstyles or tattoos (e.g., Megan Rapinoe).

The third category, Marketable Lifestyle, describes associations linked to an athlete's off-field characteristics. This dimension reflects how athletes act and interact with fans in their personal life and other instances when they are not participating in sport-related activities (Arai et al., 2013). This category has three sub-categories: life story (e.g., the extent that the athlete has an interesting or inspiring background), role model (e.g., the degree that the athlete is seen as a role model to others), and relationship effort (e.g., perceptions that the athlete cares about their fans). These off-field attributes contribute to the self-brand connection fans feel towards athletes and influence their athlete and team loyalty (Kunkel et al., 2020).

\section{The Relationship Between Philanthropy and Brand Image}

The MABI framework outlines how consumers interpret and integrate the information they encounter about athletes into an associative framework (Arai et al., 2014). This information is then used to evaluate and interpret the actions of the athlete. From this perspective, the consumer has an active role in co-creating the athlete's brand image and the salience and valence of the brand's perceptions (Batra, 2019; Woratschek, Horbel, \& Popp, 2014). From the athlete's perspective, understanding how to positively influence this associative network by better aligning their brand with consumer preferences represents a key competitive advantage (cf. Husted \& Allen, 2007). Scholars have demonstrated that better understanding consumer preferences can help guide decision making on attendance-based characteristics like ticket pricing (Kaiser, Strobel, Woratschek, \& Durchholz, 2019), showcasing the importance of the consumer as a co-creator of value within the sport context (e.g., Kolyperas, Maglaras, \& Sparks, 2019). While researchers have demonstrated strategic marketing efforts can change consumer perceptions at the team brand level (e.g., Kunkel, 
Doyle, et al., 2016), no such empirical evidence has documented how this may operate at the athlete brand level. From the athlete perspective, such changes should be made to positively impact consumer perceptions (cf. Geurin, 2017, Husted \& Allen, 2007), yet little is known about how this may occur.

Researchers have begun to examine impacts on athlete brands when individuals encounter new information about them, but this area of research has thus far focused on understanding the negative consequences emanating from instances where athletes engage in transgressions. Studies demonstrate negative information surrounding an athlete's off-field behavior (e.g., when an athlete faces criminal charges) has the potential to negatively impact consumer attitudes towards the athlete's brand (Sassenberg, 2015), associated event brands (Doyle et al., 2014), and other related team, sport, and sponsor brands (Chien, Kelly, \& Weeks 2016). Additionally, research has demonstrated that transgressions related to job performance (i.e., doping) have a stronger negative effect on consumers than transgressions not related to the job performance (i.e., fraud), because consumers can decouple from the transgression (Lee \& Kwak, 2016).

Media reporting focused on individual athletes beyond their performances are often focused on the off-field activities of athletes (Chien et al., 2016). Thus, the current research focused on how athletes may positively influence brand image perceptions through the manipulation of the Marketable Lifestyle domain. The current research also places emphasis on this domain as it is more easily controlled by the athlete than the Athletic Performance and Attractive Appearance dimensions (Arai et al., 2014). However, the MABI framework does not presently include philanthropy, despite its merits for athletes to differentiate themselves from others (e.g., Babiak et al., 2012; Tainsky \& Babiak, 2011) and its conceptual relationship to the Marketable Lifestyle domain (Arai et al., 2013; Arai et al., 2014). Consequently, people who recognize an athlete's philanthropic activities from social media 
exposure may be primed to recall the athlete's activities as unique, pleasant, or favourable. It is likely that when consumers encounter this new information, it may then become incorporated into the association set surrounding the athlete, which changes how the consumer perceives the athlete (e.g., Till, 1998).

Hypothesis 1: The promotion of philanthropic activities increases the salience of positive perceptions surrounding the athlete's Marketable Lifestyle category.

Hypothesis 2: The promotion of philanthropic activities increases positive perceptions related to the athlete as a socially responsible person.

According to social identity theory, individuals tend to associate with groups that provide positive image benefits onto their own social identities (Tajfel \& Turner, 1979). Consistent with Carlson and Donavan's (2013) research which found individuals may derive more favourable attitudes towards athletes who they perceive possess desirable characteristics, we argue that consumers may also develop strengthened attachments with athletes who support charities or causes that the consumer deems important (e.g., if an athlete supports a charity addressing a social issue close to the consumer's heart). Previous research has examined how individuals develop increased bonds with sport organizations by drawing favourable comparisons between the individual's desired social identity and that of the sport object (Doyle, Lock, Funk, Filo, \& McDonald, 2017; Kunkel et al., 2020; Lock, Taylor, Funk, \& Darcy, 2012). This research has outlined that the more congruence that exists between the individual and the focal entity (e.g., athlete, team) values and beliefs, the more positive the individual ultimately feels towards the entity. Consequently, this congruence or self-brand connection leads to a stronger overall connection that exists between the individual and athlete (Carlson \& Donavan, 2013; Kunkel et al., 2020). Research has revealed that individuals can develop into highly-connected team fans despite a lack of on-field success in 
instances where the team makes positive contributions to society (Doyle et al., 2017). Such evidence suggests that athletes may also be able to strengthen their appeal to consumers via the promotion of philanthropic activities.

Hypothesis 3: The promotion of philanthropic activities increases the overall connection that followers have with the athlete.

\section{Method}

\section{Research Design and Context}

We conducted a multi-phased study designed around two data collections and an intervention. Specifically, the research design consisted of a pre-intervention questionnaire (Time 1), an intervention, and a post-intervention questionnaire (Time 2). We collaborated with a professional athlete and focused on the use of his Instagram account. These decisions were made given the importance the Instagram platform as a branding tool (Anagnostopoulos et al., 2018) and to leverage the authenticity attached to the athlete's own account. During the research, the athlete was playing professional soccer in the United States and was also a representative of a foreign country's men's national team. We specifically chose to focus the research on one athlete to address calls to incorporate more practically relevant data collection methods within athlete-focused research (e.g., Babiak et al., 2012; Filo et al., 2015). This approach also best reflects the exploratory nature of the research and allowed us to control for confounding variables that may have burdened a larger study encompassing multiple athletes. We focused on the Instagram platform because it provides opportunities for athletes to promote their lifestyles and overall brand image (Anagnostopoulos et al., 2018; Geurin, 2017). To address the hypotheses, we collected data from social media followers of the athlete in question at two points, six months apart. Figure 1 outlines an overview of the phases in this research. 
Insert Figure 1 about here

Prior to Time 1, the athlete had been playing MLS for six seasons (three seasons with the current team at the time of data collection) and regularly participated in philanthropic activities. However, he did not promote his philanthropic work via his Instagram account prior to the intervention. Thus, the Time 1 data collection assessed the athlete's followers' attitudes towards him at a point when his Instagram was void of any strategic use of philanthropic initiatives. After data collection in Time 1, the research team helped the athlete to position his brand around his philanthropic activities, creating the motto "soccer makes a difference", and the athlete started to share posts documenting his philanthropic work (Kunkel, Scott, et al., 2016). This period acted as the intervention within the research design. As part of this intervention, the athlete promoted his philanthropic activities (e.g., building a school in Africa) via Instagram. Between Time 1 and Time 2, the athlete uploaded 159 posts, of which $21(13.2 \%)$ promoted his philanthropic activities. The data were collected before the launch of Instagram Stories, which means the athlete was not able to post ephemeral content that may have impacted the research. This intervention enabled the research team to assess the impact of adopting a strategic branding approach on consumer perceptions linked to athlete brands and to address the above stated hypotheses.

\section{Procedure}

An online questionnaire hosted by Qualtrics was utilized to collect data during Time 1 and Time 2. The athlete distributed the questionnaire to his Instagram followers through a post on his personal account directing consumers to the questionnaire. This method ensured that the sample consisted of individuals who already followed the athlete and thus were exposed to his social media activity pre- and post-intervention. We assured potential respondents that we would only share aggregate findings with the athlete to avoid biasing the sample (e.g., followers wanting to please the athlete with their responses). To encourage 
participation, respondents were entered into a random prize draw to win a soccer ball signed by the athlete or one of three Amazon gift cards (valued at $\$ 50$ each). Data consisted of two independent samples (Time 1: $N_{\mathrm{T} 1}=165$, Time 2: $\left.N_{\mathrm{T} 2}=172\right)$ and a panel sample $(N=32)$ comprised of respondents who participated in both questionnaires.

\section{Measures}

The questionnaire consisted of two parts. In the first section, we used a free-thought listing technique to uncover the associations that consumers linked to the athlete's brand image (e.g., Arai et al., 2013; Daniels et al., 2019; Kunkel et al., 2014; Ross et al., 2006). Participants were asked, "Please describe the first five thoughts that come to your mind when you think of [Athlete X]." In the second section, we collected quantitative measures to examine respondents' perceptions of the athlete's philanthropy and their level of fandom towards the athlete. We adapted three items measuring philanthropy from Öberseder, Schlegelmilch, Murphy, and Gruber's (2014) five-item Corporate Social Responsibility construct. The items were operationalized on seven-point Likert scales ranging from "1Strongly Disagree" to "7-Strongly Agree" and stated: "[Athlete X] is committed to using a portion of his income to help charitable causes", "[Athlete X] gives back to the community", and "[Athlete X] cares about other people". Cronbach's alpha $(\alpha=.73)$ for the three philanthropy items indicated that the measurements were reliable. We adapted the level of fandom measure from previous research examining the connection between individuals and teams (Na, Su, \& Kunkel, 2019). The single-item measure "Please indicate the strength of your relationship to [Athlete X]" operationalized on a seven-point Likert scale anchored with "1-Casual Observer" to "7- Hardcore Fanatic" was used to examine respondents' overall connection to the athlete.

\section{Participants}


Participants of the first independent sample (Time 1: $\left.N_{\mathrm{T} 1}=165\right)$ were on average 28.42 years old $(S D=10.34)$ and likely to be male $(77.8 \%)$. Similarly, the participants of the second independent sample (Time $\left.2: N_{\mathrm{T} 2}=172\right)$ were on average 30.18 years old $(S D=$ $10.84)$ and also predominantly male $(73.5 \%)$. Within the panel sample $(N=32)$, the participants were on average 30.59 years old $(S D=8.84)$ and mainly male $(75.0 \%)$. Thus, the two independent samples and the panel sample shared similar demographic characteristics. Respondent demographics were also consistent with the demographic characteristics of MLS fans, who are predominantly male (68\%) (Thompson, 2014) and of which roughly $40 \%$ are younger than 34 years old (Johnson, 2015). Therefore, the participants of the current study were an acceptable representation of broader MLS fan demographics, and the panel sample demographics closely mirrored the two independent samples.

\section{Data Analyses and Results}

Before we analysed the data, we cleaned the dataset to remove cases with missing data and to ensure that participants did not complete the survey in an unrealistically short timeframe. Consequently, we removed responses that were recorded in less time than it took the research team who were familiar with the research to complete. For the purposes of creating the panel sample, we matched individuals who participated in both independent samples using their email address and a unique code.

Overall, 337 independent participants entered 1,376 associations, and the 32 panel participants entered 308 associations related to the athlete. Data analysis consisted of arranging this qualitative data and subsequently assigning quantitative coding to it. Following Neumann's (2003) suggestions, we first prepared the dataset by condensing similar words (e.g. Charity, Charitable, or Charity Work), into one representative word (e.g. Charity) and eliminated common words (e.g., $A$ or The). In the first round, we coded the brand associations into the three main MABI categories and their respective sub-categories (Arai et al., 2013; 
Arai et al., 2014). These consisted of Athletic Performance (athletic expertise, competition style, sportspersonship, and rivalry), Attractive Appearance (physical attractiveness, symbol, and body fitness) and Marketable Lifestyle (life story, role model, and relationship effort). During this process, we found many brand associations did not fit into the existing MABI framework's categories or alternately, represented new sub-categories within the established higher-order MABI categories.

In the second step, we used axial coding to revise the initial codebook and include the newly-uncovered categories. The new categories and sub-categories were then discussed with an independent sport marketing academic who was not involved in the research to ensure that the data was trustworthy and to validate the additions to the codebook (cf. Daniels et al., 2019). Discussions between the researchers and the independent expert confirmed that the newly-identified sub-categories did not fit into any of the pre-existing MABI categories, thus we updated and expanded the codebook. We titled the five additional sub-categories Charity, Team/School, Sport/League, Position/Number, and Character.

In the third step, we utilized selective coding to confirm the categories and to attribute representative quotes to each (e.g., Edwards \& Skinner, 2009). After the three-round coding processes, we broadened the MABI framework (Arai et al., 2013; Arai et al., 2014) to reflect four higher-order categories consisting of 15 sub-categories. Specifically, we expanded the Marketable Lifestyle category by adding the sub-categories Charity (e.g., Schools for Salone - the name of a charity the athlete supported) and Character (e.g., Inspirational). These sub-categories describe desirable activities and traits that were coded separate from the Role Model category, because they don't necessarily reflect examples that individuals aim to emulate (e.g., followers may perceive an athlete as a philanthropist but do not personally aspire to be philanthropists). Overall, these newly identified sub-categories encompassed associations that described not only what the athlete did in his spare time, but 
also who he represented as a person. For this reason, we broadened the Marketable Lifestyle category by renaming it Marketable Life.

In addition to the three existing MABI framework categories, we also identified a fourth category comprised of brand associations that did not fit into the existing Athletic Performance, Attractive Appearance or Marketable Life categories. We named this category Sport Attributes which consisted of three sub-categories capturing the functional associations related to the athlete's Sport/League (e.g., Soccer Player), Team/School (e.g., Philadelphia Union), and Position/Number (e.g., Defensive Midfield). Finally, we attributed quantitative coding via frequency counts of each of the themes and sub-categories and verified this with the independent sport marketing academic to ensure the new category and sub-categories were conceptually different from the existing MABI classifications.

The results of the frequency analyses and the respective categories and subcategories identified are presented in Table 1, which also illustrates an example of the type of associations characterized into each category and respective sub-category. For example, respondents who associated words like "Tall" or "Muscular" with the athlete stated associations that contribute to perceptions of his Body Fitness (sub-category) within the Attractive Appearance classification. Table 1 presents quantitative counts with respect to the total number of associations linked to the athlete at Time 1 and Time 2 in both the independent and panel samples, as well as how frequently each sub-category was mentioned to assist with visualizing how perceptions towards the athlete changed between Time 1 and Time 2.

$=============$ Insert Table 1 about here

Results from the panel sample closely mirror results from the two independent samples, indicating that the panel data were representative of the overall sample. Results show that, in the post-intervention stage, the athlete's brand image was mainly shaped by 
associations related to his Character, while the fewest associations reported were related to the Attractive Appearance domain. Respondents already listed many associations related to Charity in Time 1 before the athlete actively promoted his philanthropy, and as such, these associations did not substantially grow between Time 1 and Time 2 . The main changes in brand image between Time 1 and Time 2 were related to participants' perceptions of the athlete's Character, which was mentioned more frequently in Time 2 than in Time 1 in the independent samples $\left(\mathrm{T}_{1}=35.29 \% ; \mathrm{T}_{2}=42.89 \%\right)$, as well as in the panel sample $\left(\mathrm{T}_{1}=\right.$ $\left.36.26 \% ; \mathrm{T}_{2}=44.74 \%\right)$. Thus, Hypothesis 1 was supported.

ANCOVA tests revealed significant differences for the philanthropy mean score between the two independent samples at Time 1 and Time 2, while controlling for level of fandom towards the athlete. Results presented in Table 2 show a significant main effect indicating that respondents' perception of the athlete's philanthropy were significantly higher in Time 2 than in Time 1. Effect size for partial $\eta^{2}($ small $=.02$; medium $=.13$; large $=$ above .26 ; Cohen, 1988) and Cohen's $f($ small $=.10 ;$ medium $=.25 ;$ large $=$ above $.40 ;$ Cohen, 1992) are presented to demonstrate robustness of findings. Differences between Time 1 and Time 2 and level of fandom towards the athlete explain $37.8 \%$ of the variance in respondents' perceptions of the athlete's philanthropy. We subsequently conducted ANCOVA on data from the panel of respondents $(N=32)$ who participated in both Time 1 and Time 2 to confirm respondents' perceptions changed over time. Results show a significant main effect, indicating that respondents' perception of the athlete's philanthropy was significantly higher in Time 2 than in Time 1. Differences between Time 1 and Time 2 and level of fandom towards the athlete explain $42.8 \%$ of the variance in respondents' perceptions of the athlete's philanthropy. Thus, Hypothesis 2 was supported. 
ANOVA tests revealed fandom mean differences existed between the two independent samples at Time 1 and Time 2. Results presented in Table 3 show respondents' levels of fandom were significantly higher in Time 2 than in Time 1. Subsequently, repeated measure ANOVA conducted with the panel of respondents $(N=32)$ who participated in both measurements of Time 1 and Time 2 shows the panel sample significantly increased in their level of fandom towards the athlete between Time 1 and Time 2. Thus, Hypothesis 3 was supported.

\section{$=$ Insert Table 3 about here}

Given the main changes in brand image were related to participants' perceptions of the athlete's Character, we examined how a change in character perceptions influenced panel $(N=32)$ respondents' change of fandom - labelled Fandom $\Delta$. We coded each Marketable Life association with one (1) and every other association as zero (0), resulting in scores between zero (0) and five (5) for each participant. We then subtracted the number of each individual Marketable Life associations at Time 1 from the number of each individual Marketable Life associations at Time 2 for each participant - labelled Life story $\Delta$, Role model $\Delta$, Relationship effort $\Delta$, Charity $\Delta$, and Character $\Delta$, resulting in scores between minus five (-5) and five (5) for each participant. Linear regression analysis results presented in Table 4 show the five independent variables explained $20.9 \%$ of the adjusted variance (Kvålseth, 1985) of participants’ Fandom $\Delta$, with $C$ haracter $\Delta$ being the only significant predictor. Cohen's $f^{2}$ of .264 indicated a medium effect size for the regression results (Cohen's $f^{2}:$ small $=.02 ;$ medium $=.15 ;$ large $=$ above $.35 ;$ Cohen, 1988) and the effect size of the individual indicators shows Character $\Delta$ had a large effect (Cohen's $r$ : small $=.10$; medium $=$ .30; large $=$ above .50; Cohen, 1992). These findings further support Hypothesis 3. 


\section{Discussion}

This research contributes to knowledge surrounding athlete brands by demonstrating that perceptions and overall evaluations of athlete brands can be influenced through strategic marketing (Thomson, 2006). We specifically evidence how the promotion of philanthropy via social media can change, enhance, and positively influence how consumers perceive athletes, answering calls from the literature (Kunkel, Scott, et al., 2016). The longitudinal approach used within the present research builds on previous athlete branding studies which have typically adopted a snapshot approach (Carlson \& Donavan, 2013; Geurin, 2017; Kunkel et al., 2020) to add to understanding surrounding the development and change of athlete brands over time. The present research findings demonstrate that athletes can augment the perceptions linked to their personal brands and strengthen the bonds that they possess with consumers through strategic messaging via social media. Thus, this research extends multistudy work focusing on the development and change of sport team brands (Daniels et al., 2019; Kunkel, Doyle et al., 2016) into the individual athlete context whilst also demonstrating how such effects emerge specifically across the social media context (Abeza et al., 2015; Filo et al., 2015). Consequently, these findings yield important theoretical contributions to the field of athlete branding and practical implications for individual athletes seeking to augment their brands (Geurin, 2017). Similarly, findings provide practical guidance for brand managers and agents tasked with building the brands of athlete clientele and provide support that social media platforms can be a powerful tool in developing personal brands (Su et al., 2020).

Regarding Hypothesis 1, results showed that the brand image aspect of Marketable Lifestyle became more saliently linked to the athlete over time and after the intervention where the athlete promoted his philanthropic initiatives. This result demonstrates that generic aspects can be changed if athletes uniquely brand themselves via alignment and promotion of 
their philanthropic efforts and that subtle changes in this area can influence consumer perceptions. In the present study, the focal athlete only posted philanthropy-related content a little over one in every ten posts (13.2\%); yet, he was able to shift consumer perceptions of his personal brand to include a more holistic consideration of his broader life. The high frequency of responses related to the athlete's Charity pursuits in both the independent and panel samples suggested that these elements were a significant contributor to how his overall brand image was constructed and perceived by his followers. In addition, the associations describing his Character were even more prominently recalled by respondents in both samples, demonstrating the importance that consumers place on the overall image of the athlete. For this reason, we added the Charity and Character sub-categories into the Marketable Lifestyle category, and changed the category's name to Marketable Life. The decision to rename the Marketable Lifestyle category to Marketable Life reflects the consumer perspective that this element of an athlete's brand consists of not only the things that an athlete does, but also who the athlete represents as a person. Identifying the Character sub-category complements the existing Role Model sub-category as this accounts for the core human values that followers associate with the athlete but may not wish to emulate themselves. These findings are depicted in the Revised Model of Athlete Brand Image presented in Figure 2.

$==============$ Insert Figure 2 about here

With respect to Hypothesis 2, results demonstrated that the athlete was able to positively augment his brand image by participating in and promoting his philanthropic initiatives. Researchers have discussed how athletes may be able to build strong brands based on rebellious brand images (e.g., Chang, 2018; Carlson \& Donavan, 2013), and here we evidence that the opposite is also true. These findings demonstrate that highlighting philanthropic initiatives via social media can positively impact follower perceptions of the 
athlete supporting research on corporate philanthropy (Walker \& Kent, 2013) and validating suggestions that such activities can be used to build sport brands (Parganas et al., 2015). The shift of brand associations from Sport Attributes, Attractive Appearance, and Athletic Performance to the Marketable Life associations suggest that the athlete was able to position himself as a more unique, and less generic, athlete due to his modified Instagram branding approach. In this case, consumers positively evaluated his philanthropic activities, which became important and salient associations linked to the athlete.

Examining Hypothesis 3, both independent and panel samples documented increased mean score changes with respect to the level of fandom towards the athlete from Time 1 to Time 2, thus supporting the hypothesis. This increase can be theoretically explained using tenets of social identity theory (Tajfel \& Turner, 1979), which espouses that individuals identify and build psychological connections with groups they perceive possess values and beliefs congruent with their own, or those they wish to possess (Carlson \& Donavan, 2013; Lock, Funk, Doyle, \& McDonald, 2014). In this case, it appears the athlete was able to develop a more favourable association set in the mind of his followers, and this association set contributed to an overall increase in the psychological connection between the athlete and his followers (Kunkel et al., 2020). The follow-up regression analysis shows that brand association changes from sport-specific attributes towards an overall evaluation of the athlete's Character significantly and positively influenced followers' levels of fandom towards the athlete. Overall, these results support and extend previous conceptual work (Babiak et al., 2012; Kim \& Walker, 2013) by providing empirical support that the promotion of philanthropic work positively influences consumer perceptions of athlete brands and the strength of connection that exists between an athlete and their social media followers. 


\section{Theoretical Contribution}

The current study provides two main theoretical contributions. First, this research contributes to athlete brand management literature. We demonstrate the positive impact of posting content based on largely controllable attributes (e.g., Marketable Life) not related to on-field performance, extending work that has focused on mitigating threats to brand image (Chang, 2018; Doyle et al., 2014; Lee \& Kwak, 2016; Sassenberg, 2015) and on how this may occur successfully in the team context (e.g., Doyle et al., 2017; Kunkel et al., 2016; Lock et al., 2012). As a result, the approach used in the present research validated that philanthropic activities can be utilized for both altruistic and brand management purposes. Specifically, we found that promotion of the athlete's philanthropic engagements helped to position his brand positively, influence consumers' perceptions about his brand, and impact the level of fandom reported by his followers.

In addition, this contribution extends cross-sectional work that has established athletes as brands (Carlson \& Donavan, 2008, 2013; Geurin, 2017; Kunkel et al., 2020) by demonstrating how consumer brand attitudes can be strategically modified via longitudinal marketing messaging. As such, we address calls for longitudinal work focused on individual athletes, illuminating knowledge surrounding athlete brand development (Kunkel, Scott, et al., 2016). The longitudinal nature of this research demonstrated that through strategically controlling social media posts, the athlete was able to shift the top-of-mind associations attributed to him from generic associations (e.g., Sport Attributes), to those that are more unique (e.g., Marketable Life) and thus, developed a more positive and distinct brand. Consistent with previous research findings (Carlson \& Donavan, 2013), it is likely that respondents in this research possessed more favourable perceptions of the athlete based on his image better aligning with respondents' desired sense of self (Tajfel \& Turner, 1979) or through the creation of values and beliefs that were aligned with a positive cause (e.g., Filo et 
al., 2009). Furthermore, within this research, we specifically assessed how athletes can use social media (rather than other promotional channels or activities) for brand building purposes. Our findings contribute to the limited, yet emerging literature base concentrated on athletes' use of social media (Abeza et al., 2015; Filo et al., 2015) through specifically demonstrating how philanthropic social media content can be used to positively shape consumer perceptions of athlete brands and the overall level of connection and interest consumers have in following an athlete (Kunkel et al., 2020).

Second, we extend the athlete branding literature by validating and building upon previous conceptual work outlining the components which contribute to an athlete's overall brand image (Arai et al., 2014). The most salient associations linked to the athlete within the present research were related to his Marketable Life, with the newly-discovered Charity and Character association types representing the two most prominently recalled sub-categories of associations. This suggests that Charity and Character associations can represent central components of an athlete's brand, yet previous research has not conceptualised these aspects as important contributors to consumers' overall perceptions of athlete brands. Consequently, we contribute the Revised Model of Athlete Brand Image (Figure 2) incorporating these subthemes to capture a broader appreciation of the athlete's off-field endeavours, representing not only what the athlete does (e.g., invest effort in building relationships with fans), but also who they represent as a person (e.g., their character). Additionally, our findings support adding the Sport Attributes category to the revised MABI framework as a fourth higher-order category. This newly identified component represents functional attributes linked to the athlete. These functional associations are not present in previous brand association research focused on teams and leagues (e.g., Daniels et al., 2019; Kunkel, et al., 2014; Parganas et al., 2015) and have also not been included in the MABI framework to date. Yet, findings illustrate the associations formed a frequently recalled component of the athlete's brand in 
this study. Although some of the functional attributes surrounding an athlete may appear trivial, this research revealed Sport Attributes like the athlete's representative league, team, position, and playing number, were important brand associations that contributed to how consumers perceived his brand. In fact, the proportion of Sport Attribute associations listed was higher than that of those attributed to the Attractive Appearance theme - thus warranting inclusion in a revised MABI framework.

This finding shows that team-related attributes play a role in how consumers evaluate an athlete's brand image, supporting conceptual propositions put forth in prior work (Hasaan et al., 2018). Elsewhere, previous work supports that the presence of star players can benefit their representative teams and leagues via stimulating increased sales and attendance (Shapiro, DeSchriver, \& Rascher, 2017) and through being perceived as relevant team brand associations (Daniels et al., 2019). Similarly, social media focused scholarship has demonstrated that interest in individual athlete content can generate higher interest in the athlete's representative team account (Su et al., 2020; Watanabe, Yan, \& Soebbing, 2016). Thus, the present research supports the propositions of the sport brand ecosystem (Kunkel \& Biscaia, 2020) and sport brand architecture (Kunkel et al., 2013) by showing how consumer perceptions attached to master-level brands (e.g., league or team) impact evaluations of subbrands (e.g., athletes) in a portfolio and vice versa. Finally, the Sport Attributes theme also confirmed that functional attributes like an athlete's playing number are important to consumers, providing empirical support to decisions from certain athletes to pursue wearing a particular number (e.g., the number 23 by Michael Jordan) inherently linked to their brands.

\section{Practical Implications}

The findings of the current study provide athletes with a basis to develop their personal brands via leveraging their philanthropic work. Scholars suggest that evidence of strategy guiding athletes' social media use is lacking (Geurin, 2017), and the current research 
helps to address this gap. Many athletes already engage in philanthropic pursuits by rallying behind social causes. While these altruistic pursuits provide considerable benefits to the organisations and individuals impacted by them, our findings suggest that athletes can also leverage this work to build their personal brands and impact how they are perceived by consumers. This provides valuable implications for both high profile athletes and those who are not as well known (e.g., niche sport athletes or collegiate athletes).

This research demonstrated how philanthropic posts integrated across athletes' social media strategy can help athletes with the repositioning and strengthening of their brands (cf. Husted \& Allen, 2007). Athletes need to continually engage in strategic brand building to maximise their earning potential and to combat potential negative information that may be associated with their brands. Given consumer perceptions associated with the Marketable Life domain are easier to manipulate than those in the Athletic Performance or Attractive Appearance dimensions (e.g., Arai et al., 2014) we suggest strategically incorporating philanthropy into athletes' social media posting approach (cf. Husted \& Allen, 2007) as our findings suggest that consumers also experienced a strengthening of overall fandom towards the athlete.

Based on the above, athletes that are engaged in philanthropic work should incorporate Marketable Life posts into their social media strategy. Although the extent to which an athlete may engage in philanthropy may vary from low-profile volunteering to managing large foundations, each philanthropic pursuit may play a role in helping the athlete build a unique and positive brand and thus should be publicised. Athletes who are not currently engaged in philanthropy are encouraged to rectify this for both altruistic and brand management reasons. In doing so, athletes should carefully identify causes that are aligned with their brand and that are of interest to them, their current followers, and their potential followers (e.g., Batra, 2019; Kaiser et al., 2019; Kolyperas et al., 2019), as perceived value is 
co-created by consumers (cf. Woratschek et al., 2014). Given their reach via social media, athletes can garner feedback through surveying their existing followers or surveying a potential target audience via promoted polls if they are not sure where to direct their efforts. While there are benefits of partnering with reputable charities, such as not having to navigate legal aspects of registering an organization, athletes starting their own charity or foundation may reap long-term benefits, such as strategically deciding how the organization contributes to society and being the face of the charity, which may lead to heightened social impacts and more pronounced and positive brand impacts. But most importantly, we advocate athletes to remain authentic in their philanthropic approaches and contribute to causes for which they personally care.

\section{Limitations and Future Research}

This research possessed two main limitations that should be addressed by future research. The first limitation relates to the research design used. The exploratory nature of the research meant that we focused on the Instagram activity of a single team sport athlete only. This focus allowed the research team to work closely with the athlete and to better control for external variables that may have otherwise confounded the results (e.g., Parganas et al., 2015). However, further research should assess the short- and long-term impacts of personal branding in a variety of sport settings - including athletes from both team and individual sports, across a verity of levels, and spanning geographic regions. Similarly, research assessing the role of gender on perceptions of personal branding initiatives would also yield valuable insights, given the additional branding challenges faced by female athletes (Lobpries et al., 2018).

The second limitation relates to the employed data collection procedures. While obtaining longitudinal samples via social media using real athletes is difficult and seldom attempted, our findings should be further validated in future research with larger sample sizes 
and more athletes. Additionally, between Time 1 and Time 2, the athlete posted photos of his philanthropy initiatives, commented about social problems, and encouraged participation in charity campaigns. However, complete control for external sources promoting his philanthropy efforts, such as the team or fans sharing information about the athlete's philanthropy, could not be controlled for. Similar research including a control group of respondents who are not exposed to the athlete's philanthropic posts would be one way to better isolate the effects of this form of promotion. Researchers should also examine the effect of ephemeral content (Wakefield \& Bennett, 2018), such as Instagram Stories, and whether a 'more is better' approach is fruitful or if too many philanthropy posts detrimental effect on consumer perceptions because of over-exposure (e.g., Berman, Levine, Barasch, \& Small, 2015) or perceptions of bragging behavior (Na, Kunkel, \& Doyle, 2020).

The rise of athlete activism provides additional opportunities for future research. While negative associations were not uncovered in the current research, it is possible that some subsets of consumers may dislike it when athletes engage in social activism or when they promote their philanthropic activity via social media as such actions may be perceived as inappropriate or as a branding tactic (e.g., Friestad \& Wright, 1999). For example, Colin Kaepernick kneeling during the national anthem to protest against police brutality is seen as controversial by some fans and positive by others. Thus, future research should investigate how athletes use social media to communicate social causes and the impact of athlete activism on their personal brand image.

\section{Conclusion}

Overall, this research extends understandings of athlete brand management, with a specific focus on how this may occur across social media channels. Findings from longitudinal research indicate that philanthropic activities impacted the brand associations consumers' linked to the athlete, with a decrease of generic associations and an increase of 
unique associations reflecting the athlete's Character. Additionally, promotion of the athlete's philanthropic activities increased consumer perceptions that the athlete was socially responsible, and positively impacted their overall fandom towards the athlete. These findings contribute to theoretical knowledge governing athlete brands and provide implications for practitioners to utilize strategic philanthropic activities as part of constructing and managing how an athlete's brand may be perceived by consumers. 


\section{References}

Abeza, G., O’Reilly, N., \& Reid, I. (2013). Relationship marketing and social media in sport. International Journal of Sport Communication, 6(2), 120-142.

Abeza, G., O’Reilly, N., Séguin, B., \& Nzindukiyimana, O. (2015). Social media scholarship in sport management research: A critical review. Journal of Sport Management, 29(6), 601-618.

Anagnostopoulos, C., Parganas, P., Chadwick, S., \& Fenton, A. (2018). Branding in pictures: using Instagram as a brand management tool in professional team sport organizations. European Sport Management Quarterly, 18(4), 413-438.

Arai, A., Ko, Y. J., \& Kaplanidou, K. (2013). Athlete brand image: Scale development and model test. European Sport Management Quarterly, 13(4), 383-403.

Arai, A., Ko, Y. J., \& Ross, S. (2014). Branding athletes: Exploration and conceptualization of athlete brand image. Sport Management Review, 17(2), 97-106.

Babiak, K., Mills, B., Tainsky, S., \& Juravich, M. (2012). An investigation into professional athlete philanthropy: Why charity is part of the game. Journal of Sport Management, 26(2), 159-176.

Baalbaki, S., \& Guzmán, F. (2016). A consumer-perceived consumer-based brand equity scale. Journal of Brand Management, 23(3), 229-251.

Batra, R. (2019). Creating brand meaning: a review and research agenda. Journal of Consumer Psychology, 29 (3), 535-546.

Berman, J. Z., Levine, E. E., Barasch, A., \& Small, D. A. (2015). The braggart's dilemma: On the social rewards and penalties of advertising prosocial behavior. Journal of Marketing Research, 52(1), 90-104. 
Braunstein, J., \& Zhang, J. (2005). Dimensions of athletic star power associated with generation Y sports consumption. International Journal of Sports Marketing and Sponsorship, 6(4), 242-267.

Carlson, B. D., \& Donavan, D. T. (2008). Concerning the effect of athlete endorsements on brand and team-related intentions. Sport Marketing Quarterly, 17(3), 154-162.

Carlson, B. D., \& Donavan, D. T. (2013). Human brands in sport: Athlete brand personality and identification. Journal of Sport Management, 27(3), 193-206.

Chang, Y. (2018). When infamy becomes fame: The positive side of negative athlete publicity. Journal of Sport Management, 32(4), 401-411.

Choi, S.M. \& Berger, R. (2010). Ethics of celebrities and their increasing influence in 21st century society. Journal of Business Ethics, 91(3), 313-318.

Chien, P. M., Kelly, S. J., \& Weeks, C. S. (2016). Sport scandal and sponsorship decisions: Team identification matters. Journal of Sport Management, 30(5), 490-505.

Cohen, J. (1988). Statistical power analysis for the behavioral sciences, 2 nd edition. New York: Erlbaum

Cohen, J. (1992). A power primer. Psychological Bulletin. 112(1), 155-159.

Daniels, J., Kunkel, T., \& Karg, A. (2019). New brands: contextual differences and development of brand associations over time. Journal of Sport Management, 33(2), 133147.

Doyle, J.P., Filo, K., McDonald, H., \& Funk, D.C. (2013). Exploring sport brand double jeopardy: The link between team market share and attitudinal loyalty. Sport Management Review, 16, 285-297.

Doyle, J. P., Filo, K., Lock, D., Funk, D. C., \& McDonald, H. (2016). Exploring PERMA in spectator sport: Applying positive psychology to examine the individual-level benefits of sport consumption. Sport Management Review, 19(5), 506-519. 
Doyle, J. P., Lock, D., Funk, D. C., Filo, K., \& McDonald, H. (2017). 'I was there from the start': The identity-maintenance strategies used by fans to combat the threat of losing. Sport Management Review, 20(2), 184-197.

Doyle, J. P., Pentecost, R. D., \& Funk, D. C. (2014). The effect of familiarity on associated sponsor and event brand attitudes following negative celebrity endorser publicity. Sport Management Review, 17(3), 310-323.

Edwards, A., \& Skinner, J. (2009). Qualitative research in sport management. Oxford: Elsevier.

FIFPro (2015, December 12). Lahoud and Kamara earn merit award. Retrieved from https://fifpro.org/news/michael-lahoud-and-kei-kamara-earn-meritaward/en/?highlight=WyJjaGFyaXR5IiwiY2hhcml0eSdzIl0=

Filo, K., Funk, D. C., \& O’Brien, D. (2009). The meaning behind attachment: Exploring camaraderie, cause, and competency at a charity sport event. Journal of Sport Management, 23(3), 361-387.

Filo, K., Lock, D., \& Karg, A. (2015). Sport and social media research: A review. Sport Management Review, 18(2), 166-181.

Friestad, M., \& Wright, P. (1999). Everyday persuasion knowledge. Psychology \& Marketing, 16(2), 185-194.

Funk, D. C., \& James, J. (2001). The psychological continuum model: A conceptual framework for understanding an individual's psychological connection to sport. Sport Management Review, 4(2), 119-150.

Funk, D. C., \& James, J. D. (2006). Consumer loyalty: The meaning of attachment in the development of sport team allegiance. Journal of Sport Management, 20(2), 189-217. Geurin, A. N. (2017). Elite female athletes' perceptions of new media use relating to their careers: A qualitative analysis. Journal of Sport Management, 31(4), 345-359. 
Geurin-Eagleman, A. N., \& Burch, L. M. (2016). Communicating via photographs: A gendered analysis of Olympic athletes' visual self-presentation on Instagram. Sport Management Review, 19(2), 133-145.

Gladden, J. M., \& Funk, D. C. (2001). Understanding brand loyalty in professional sport: Examining the link between brand associations and brand loyalty. International Journal of Sports Marketing and Sponsorship, 3(1), 54-81.

Guzmán, F., \& Davis, D. (2017). The impact of corporate social responsibility on brand equity: consumer responses to two types of fit. Journal of Product \& Brand Management, 26(5), 435-446.

Hasaan, A., Kerem, K., Biscaia, R., \& Agyemang, K. (2018). A conceptual framework to understand the creation of athlete brand and its consequences. International Journal of Sports Marketing and Management, 18(3), 169-198.

Hayes, M., Filo, K., Geurin, A., \& Riot, C. (2020). An exploration of the distractions inherent to social media use among athletes. Sport Management Review. https://doi.org/10.1016/j.smr.2019.12.006

Hodge, C. \& Walker, M. (2015). Personal branding: A perspective from the professional athlete-level-of-analysis. International Journal of Sport Management and Marketing, 16(1-2), 112-131.

Husted, B. W. \& Allen, D. B. (2007). Corporate social strategy in multinational enterprises: Antecedents and value creation. Journal of Business Ethics, 74, 345-361.

Johnson, A. (2015, May 27). Soccer by the numbers: A look at the game in the U.S. NBCnews. Retrieved from http://www.nbcnews.com/storyline/fifa-corruptionscandal/soccer-numbers-look-game-u-s-n365601 
Kaiser, M., Ströbel, T., Woratschek, H., \& Durchholz, C. (2019). How well do you know your spectators? A study on spectator segmentation based on preference analysis and willingness to pay for tickets. European Sport Management Quarterly, 19(2), 178-200.

Keller, K. L. (1993). Conceptualizing, measuring, and managing customer-based brand equity. Journal of Marketing, 57(1), 1-22.

Kim, M., \& Walker, M. (2013). The influence of professional athlete philanthropy on donation intentions. European Sport Management Quarterly, 13(5), 579-601.

Kolyperas, D., Maglaras, G., \& Sparks, L. (2019). Sport fans’ roles in value cocreation. European Sport Management Quarterly, 19(2), 201-220.

Knoblauch, A. (2018, February 3). J.J. Watt named Walter Payton NFL man of the year. NFL.com. Retrieved from http://www.nfl.com/news/story/0ap3000000913855/article/jjwatt-named-walter-payton-nfl-man-of-the-year

Kunkel, T. \& Biscaia, R. (2020). Sport brands - Brand relationships and consumer behavior. Sport Marketing Quarterly. 29(1). 3-16.

Kunkel, T., Biscaia, R., Arai, A., \& Agyemang, K. (2020). The role of self-brand connection on the relationship between athlete brand image and fan outcomes. Journal of Sport Management. 34(3). 201-216.

Kunkel, T., Doyle, J. P., Funk, D. C., Du, J., \& McDonald, H. (2016). The development and change of brand associations and their influence on team loyalty over time. Journal of Sport Management, 30(2), 117-134.

Kunkel, T., Funk, D., \& Hill, B. (2013). Brand architecture, drivers of consumer involvement, and brand loyalty with professional sport leagues and teams. Journal of Sport Management, 27(3), 177-192.

Kunkel, T., Funk, D., \& King, C. (2014). Developing a conceptual understanding of consumer-based league brand associations. Journal of Sport Management, 28(1), 49-67. 
Kunkel, T., Scott, O., \& Beaton, A. (2016). Interview with Michael Lahoud, professional soccer player: Lessons of personal athlete branding via social media. International Journal of Sport Communication, 9(4), 415-423.

Kvålseth, T. O. (1985). Cautionary note about R ${ }^{2}$. The American Statistician, 39(4), 279-285.

Lee, J. S., \& Kwak, D. H. (2016). Consumers' responses to public figures' transgression:

Moral reasoning strategies and implications for endorsed brands. Journal of Business Ethics, 137, 101-131.

Lobpries, J., Bennett, G., \& Brison, N. (2018). How I perform is not enough: Exploring branding barriers faced by elite female athletes. Sport Marketing Quarterly, 27(1), 5-17. Lock, D., Darcy, S., \& Taylor, T. (2009). Starting with a clean slate: An analysis of member identification with a new sports team. Sport Management Review, 12(1), 15-25.

Lock, D., Funk, D. C., Doyle, J. P., \& McDonald, H. (2014). Examining the longitudinal structure, stability, and dimensional interrelationships of team identification. Journal of Sport Management, 28(2), 119-135.

Lock, D., Taylor, T., Funk, D., \& Darcy, S. (2012). Exploring the development of team identification. Journal of Sport Management, 26(4), 283-294.

McAlister, D. T., \& Ferrell, L. (2002). The role of strategic philanthropy in marketing strategy. European Journal of Marketing, 36(5/6), 689-705.

Na, S., Kunkel, T. , \& Doyle, J. P. (2020). Exploring athlete brand image development on social media: The role of signalling through source credibility. European Sport Management Quarterly, 20, 88-108.

Neumann, L. W. (2003). Social research methods: Qualitative and quantitative approaches (5th ed.). Boston, MA: Allyn and Bacon.

MLS WORKS (2019). MLS WORKS. Retrieved from https://www.mlssoccer.com/mlsworks 
Öberseder, M., Schlegelmilch, B. B., Murphy, P. E., \& Gruber, V. (2014). Consumers’ perceptions of corporate social responsibility: scale development and validation. Journal of Business Ethics, 124(1), 101-115.

Parganas, P., Anagnostopoulos, C., \& Chadwick, S. (2015). 'You'll never tweet alone': Managing sports brands through social media. Journal of Brand Management, 22(7), $551-568$.

Ross, S., James, J., \& Vargas, P. (2006). Development of a scale to measure team brand associations in professional sport. Journal of Sport Management, 20(2), 260-279.

Sassenberg, A. (2015). Effects of sport celebrity transgressions: An exploratory study. Sport Marketing Quarterly, 24(2), 78-90.

Shapiro, S. L., DeSchriver, T. D., \& Rascher, D. A. (2017). The Beckham effect: examining the longitudinal impact of a star performer on league marketing, novelty, and scarcity. European Sport Management Quarterly, 17(5), 610-634.

Su, Y., Baker, B., Doyle, J. P., \& Kunkel, T. (2020). Rise of an athlete brand: Factors influencing the social media following of athletes. Sport Marketing Quarterly. 29(1). 3245.

Tainsky, S. \& Babiak, K. (2011). Professional athletes and charitable foundations: An exploratory investigation. International Journal of Sport Management and Marketing, $9(3-4), 133-153$.

Tajfel, H. \& Turner, J. (1979). An integrative theory of intergroup conflict. In W. Austin \& S. Worchel (Eds.), The social psychology of intergroup relations (p. 33-47). Monterey: Brooks-Cole Publishing Company.

Thomson, M. (2006). Human brands: Investigating antecedents to consumers' strong attachments to celebrities. Journal of Marketing, 70(3), 104-119. 
Thompson, D. (2014, February 10). Which sports have the whitest/richest/oldest fans? The Athlantic. Retrieved from https://www.theatlantic.com/business/archive/2014/02/whichsports-have-the-whitest-richest-oldest-fans/283626/

Till, B. D. (1998). Using celebrity endorsers effectively: Lessons from associative learning. Journal of Product and Brand Management, 7(5), 400-409.

Trackalytics (2017). JJ Watt Twitter profile. Trackalytics.com. Retrieved from https://www.trackalytics.com/twitter/profile/jjwatt/

Walker, M. \& Kent, A. (2013). The roles of credibility and social consciousness in the corporate philanthropy-consumer behavior relationship. Journal of Business Ethics, 116(2), 341-353.

Watanabe, N. M., Yan, G., \& Soebbing, B. P. (2016). Consumer interest in Major League Baseball: An analytical modeling of Twitter. Journal of Sport Management. 30(2), 207220.

Woratschek, H., Horbel, C., \& Popp, B. (2014). The sport value framework - a new fundamental logic for analyses in sport management. European Sport Management Quarterly, 14(1), 6-24. 
Table 1:

Frequency analysis of athlete brand associations

\begin{tabular}{|c|c|c|c|c|c|c|}
\hline \multirow{2}{*}{ Theme } & \multirow{2}{*}{ Sub-category } & \multirow{2}{*}{ Example } & \multicolumn{2}{|c|}{ Independent Sample (\%) } & \multicolumn{2}{|c|}{ Panel Sample (\%) } \\
\hline & & & Time 1 & Time 2 & Time 1 & Time 2 \\
\hline \multirow{5}{*}{$\begin{array}{l}\text { Athletic } \\
\text { Performance }\end{array}$} & Athletic expertise & Skilled / Dominating & 10.08 & 10.50 & 12.82 & 9.24 \\
\hline & Competition style & Charismatic / Aggressive & 9.41 & 9.48 & 10.90 & 10.50 \\
\hline & Sportspersonship & Fair play & 0 & 0.38 & 0 & 0 \\
\hline & Rivalry & Names of other players & 0.84 & 0.64 & 0 & 0 \\
\hline & Total & & 20.34 & 21.00 & 23.72 & 19.74 \\
\hline \multirow{4}{*}{$\begin{array}{l}\text { Attractive } \\
\text { Appearance }\end{array}$} & Physical attractiveness & Attractive / Sexy & 1.85 & 0.77 & 0.64 & 0.66 \\
\hline & Symbol & Hair style / Fashionable & 2.52 & 0.77 & 1.28 & 0.66 \\
\hline & Body fitness & Tall / Muscular & 2.02 & 1.41 & 1.28 & 0 \\
\hline & Total & & 6.39 & 2.94 & 3.21 & 1.32 \\
\hline \multirow{6}{*}{$\begin{array}{l}\text { Marketable } \\
\text { Life }\end{array}$} & Life story & Africa / Civil War & 6.22 & 4.87 & 5.77 & 6.58 \\
\hline & Role model & Hero / Role Model & 1.85 & 2.05 & 1.92 & 3.29 \\
\hline & Relationship effort & Cares for Fans / Loves Fans & 3.87 & 2.82 & 5.77 & 1.32 \\
\hline & Charity & Schools for Salone / Philanthropy & 12.44 & 13.32 & 15.03 & 14.47 \\
\hline & Character & Kind / Inspirational / Funny & 35.29 & 42.89 & 36.26 & 44.74 \\
\hline & Total & & 59.66 & 65.94 & 64.74 & 70.39 \\
\hline \multirow{4}{*}{$\begin{array}{l}\text { Sport } \\
\text { Attributes }\end{array}$} & Sport / League & Soccer / MLS player & 5.55 & 3.33 & 1.92 & 2.63 \\
\hline & Team / School & Philadelphia / Wake Forest & 4.37 & 4.23 & 3.21 & 3.95 \\
\hline & Position / Number & Midfielder / Number 13 & 3.70 & 2.56 & 3.21 & 1.97 \\
\hline & Total & & 13.61 & 10.12 & 8.33 & 8.55 \\
\hline \multicolumn{3}{|c|}{ Total Number of Associations } & 595 & 781 & 156 & 152 \\
\hline
\end{tabular}


Table 2

ANCOVA results for perception of philanthropy

\begin{tabular}{|c|c|c|c|c|c|c|c|c|c|}
\hline & \multicolumn{2}{|c|}{ Time 1} & \multicolumn{2}{|c|}{ Time 2} & \multicolumn{3}{|c|}{ Univariate Tests } & \multicolumn{2}{|c|}{$\begin{array}{c}\text { Pairwise } \\
\text { Comparisons }\end{array}$} \\
\hline & $M$ & $S D$ & $M$ & $S D$ & $F$ & $p$ & $\begin{array}{c}\text { partial } \\
\eta^{2}\end{array}$ & Groups & $p$ \\
\hline $\begin{array}{l}\text { Independent } \\
\text { Sample }\end{array}$ & 5.73 & .80 & 6.49 & .59 & 100.69 & $<.001$ & .378 & $\mathrm{~T} 1<\mathrm{T} 2$ & $<.001$ \\
\hline$(N=337)$ & & $\beta$ & \multicolumn{2}{|c|}{$t$} & $p$ & \multicolumn{2}{|c|}{ partial $\eta^{2}$} & \multicolumn{2}{|c|}{ Cohen'sf } \\
\hline Difference T1vs.T2 & & .68 & \multicolumn{2}{|c|}{9.79} & $<.001$ & \multicolumn{2}{|r|}{.225} & \multicolumn{2}{|c|}{.538} \\
\hline Level of fandom & & .20 & \multicolumn{2}{|c|}{9.01} & $<.001$ & \multicolumn{2}{|r|}{.197} & \multicolumn{2}{|c|}{.495} \\
\hline \multirow[t]{2}{*}{$\begin{array}{l}\text { Panel sample } \\
(N=32)\end{array}$} & 5.78 & .87 & 6.66 & .37 & 18.78 & $<.001$ & .428 & $\mathrm{~T} 1<\mathrm{T} 2$ & $<.001$ \\
\hline & & $\beta$ & \multicolumn{2}{|c|}{$t$} & $p$ & \multicolumn{2}{|r|}{ partial $\eta^{2}$} & \multicolumn{2}{|c|}{ Cohen's $f$} \\
\hline Difference T1vs.T2 & & .83 & \multicolumn{2}{|c|}{5.41} & $<.001$ & \multicolumn{2}{|r|}{.324} & \multicolumn{2}{|c|}{.692} \\
\hline Level of fandom & & .18 & \multicolumn{2}{|c|}{3.52} & $<.001$ & \multicolumn{2}{|r|}{.169} & \multicolumn{2}{|c|}{.451} \\
\hline
\end{tabular}


Table 3

ANOVA results for level of fandom towards athlete

\begin{tabular}{lccccccc}
\hline & \multicolumn{2}{c}{ Time 1} & \multicolumn{2}{c}{ Time 2} & \multirow{2}{*}{$F$} & & \multicolumn{2}{c}{ partial } \\
\cline { 2 - 5 } & $M$ & $S D$ & $M$ & $S D$ & & & $\eta^{2}$ \\
\hline $\begin{array}{l}\text { Independent Sample } \\
(N=337)\end{array}$ & 4.65 & 1.64 & 5.03 & 1.39 & 5.138 & .024 & .015 \\
\hline $\begin{array}{l}\text { Panel sample } \\
(N=32)\end{array}$ & 5.12 & 1.60 & 5.41 & 1.27 & 4.765 & .037 & .133 \\
\hline
\end{tabular}


Table 4

Regression results for the change of level of fandom towards athlete

Unstand. $\beta \quad$ Std. Error $\quad$ Stand. $\beta$

\begin{tabular}{lcccccc} 
& Unstand. $\beta$ & Std. Error & Stand. $\beta$ & $t$ & $p$ & $r$ \\
\hline Overall model & .295 & .196 & & 1.504 & .145 & \\
Constant & .092 & .388 & .042 & .238 & .814 & .092 \\
Life story $\Delta$ & .378 & .384 & .172 & .984 & 334 & .222 \\
Role model $\Delta$ & .214 & .187 & .190 & 1.143 & .263 & .240 \\
Relationship effort $\Delta$ & .052 & .213 & .043 & .243 & .810 & .093 \\
Charity $\Delta$ & .482 & .153 & .542 & 3.163 & .004 & .592 \\
Character $\Delta$ & $F(5,26)=2.641, p=.046 ;$ & Adjusted $R^{2}=.209 ;$ Cohen's $f^{2}=.264$ \\
\hline
\end{tabular}


Figure 1

Overview of data collection process

\begin{tabular}{|c|c|c|}
\hline Time 1 & $\begin{array}{c}\text { Intervention } \\
\text { Philanthropy Strategy } \\
\text { Pre-Philanthropy } \\
\text { Promotion Survey } \\
159 \text { posts of which 21 promoted } \\
\text { philanthropy activities }\end{array}$ \\
\hline
\end{tabular}

Figure 2

Revised Model of Athlete Brand Image

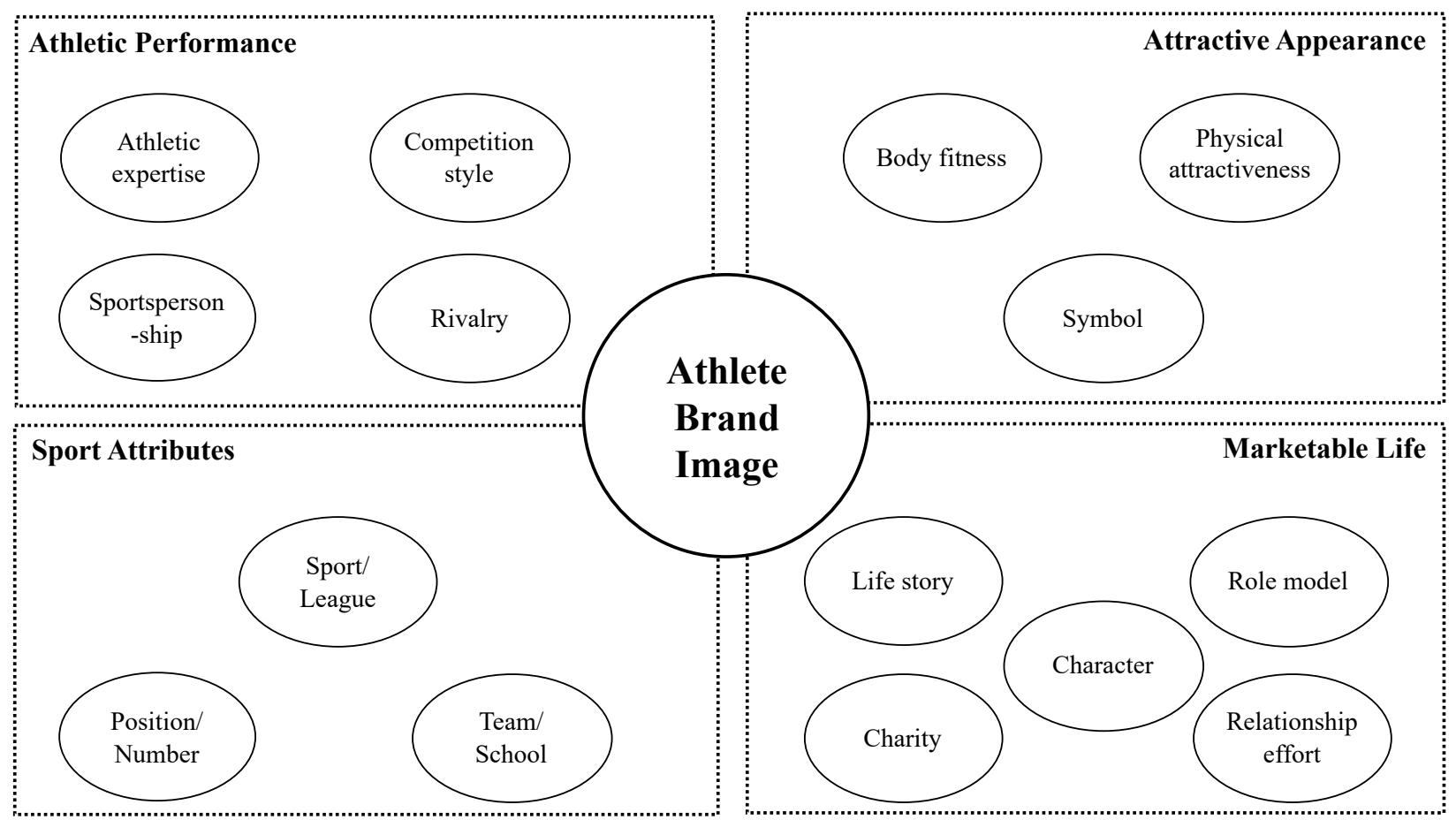

